PIOTR Minias ${ }^{1}$, KRZYSZTOF KACZMAREK ${ }^{2}$, RAdOSŁAW WŁODARCZYK ${ }^{1} \&$ TOMASZ JANISZEWSKI $^{1}$

${ }^{1}$ Department of Teacher Training and Biodiversity Studies, University of Łódź, Banacha 1/3, 90-237 Łódź, Poland, pminias@op.pl

${ }^{2}$ Medical University of Łódź, Kościuszki 4, 91-425 Łódź, Poland

\title{
PATTERN OF POST-JUVENILE MOULT IN COMMON SNIPE (GALLINAGO GALLINAGO) AND ITS IMPLICATIONS FOR AGEING OF THE SPECIES
}

\begin{abstract}
External ageing of Common Snipe (Gallinago gallinago) still engenders considerable problems. To improve precision of age determination on the basis of plumage characteristics a scheme of post-juvenile moult was investigated in approximately 1200 first-year Common Snipes caught during autumn migration in central Poland. Post-juvenile moult was commenced from body feathers followed by moult of rectrices, lesser/median wing coverts and tertials. Moult sequence showed high inter-individual variability and was started in rectrices (36.9\%), wing coverts $(25.3 \%)$, tertials $(8.4 \%)$ or simultaneously in several of these tracts of feathers (29.4\%). Moult of rectrices was finished before completion of moult of wing coverts and tertials. Moult of tertials finished as the last from all age-indicative tracts of feathers. Consequently, tertials were suggested as the most useful for ageing of firstyear Common Snipes in an advanced stage of moult. There was no case of moult of the outermost tertial in first-year birds. The second tertial from distal side of wing was moulted as the last one within this tract of feathers and thereby should be of special interest during plumage examination.
\end{abstract}

Key words: feather replacement, moult sequence, waders, Charadrii, Poland 


\section{INTRODUCTION}

Common Snipe (Gallinago gallinago) is one of a few Palaearctic waders which still engender considerable problems in external ageing. Impossibility of age determination is closely associated with moult scheme typical for the species. Firstyear snipes during the post-juvenile moult replace all tracts of feathers which are, according to the current state of knowledge, diagnostic for age identification. These are namely lesser and median coverts, scapulars, tertials and rectrices (GLUTZ VON Blotzheim et al. 1977). As the plumage attained by first-year snipes after conclusion of post-juvenile moult is indistinguishable from the one of adults, all individuals which completed moult during the autumn migration are impossible to age (FOGARTY et al. 1977). Apart from standard plumage examination a number of other methods were suggested to be useful in external ageing of Common Snipe. A degree of wear of flight-feathers was surmised to differ between age groups, due to looser structure of vanes in first-year birds, which makes them more prone to abrasion and bleaching (PRATER et al. 1977). Although this criterion proved satisfactory in the Great Snipe (Gallinago media) and a number of other wader species (SÆTHER et al. 1994), in Common Snipe such contrast is extremely difficult (or usually not possible) to notice during standard bird examination and strongly depends on light conditions. Thus, the method is highly erroneous and should rather not be applied during fieldworks (STRANDGAARD 1986). Another approach to ageing methodology employed in Gallinago genus was discriminant analysis of morphological measurements. Nevertheless, distcriminant functions were developed only for the Wilson's Snipe (G. delicata), in which the most accurate equations allowed correct ageing of $66-82 \%$ of males and $73-84 \%$ of females (MCCLOSKEY, THOMPSON 2000). In the case of Eurasian subspecies of Common Snipe (G. $g$. gallingo) discriminant functions were so far proved useful only in sex identification (GREEN 1991). Colour of bill and legs was also suggested to be age-dependent and consequently proposed as a reliable ageing criterion (TUCK 1972). This method however appeared to be relatively accurate only at the beginning of migration period, but it failed to be applicable later, as the moult progressed (WHITEHEAD 1965; HoFFPAUIR 1969). Lack of any universal ageing criteria means that by the 
time some new methods are developed, standard plumage examination procedures will have to prevail. Therefore, maximization of efficiency of snipe ageing on the basis of plumage characteristics seems indispensable in the field studies on this species. In Common Snipe colours and patterning of feathers are extremely complex and show high inter-individual variation, which further impedes ageing attempts. Thereby detailed knowledge on the moult sequence of this species is needed, as it would indicate potentially most age-revealing tracts of feathers. Only under these conditions effective examination of bird plumage will be possible and the rate of individuals with undetermined age is likely to reach irreducible minimum. The data on the moult of Common Snipe are scarce and descriptive, usually confined to a phenological approach (OAG MÜNSTER 1975; DEVORT 1997; ROUXEL 2000). The aim of this study is to provide quantitative data on the post-juvenile moult of Common Snipe and to improve precision of existing methods of its external ageing.

\section{METHODS}

Common Snipes were caught at Jeziorsko reservoir $\left(51^{\circ} 73^{\prime} \mathrm{N}, 18^{\circ} 63^{\prime} \mathrm{E}\right)$ in central Poland. Walk-in traps and mist-nets were used, but their number and localization was variable and dependent on the water level (BARGIEL et al. 1998). The data were collected during the years 2004-2007. A study period during all the years of research lasted from the beginning of July until the end of September. The time of fieldworks covered the main autumn migration wave of Common Snipe through central Poland (JANISZEWSKI et al. 1998; TOMIAŁOJĆ, STAWARCZYK 2003). Moult phenology of snipes migrating through Jeziorsko reservoir was described in details by MINIAS and others (2010). All birds were ringed and measured according to the standard procedures (BUSSE 2000). In total, 1383 snipes were caught throughout all years of study. Age determination was based on the combination of standard diagnostic features, including patterning of tertials, lesser/median coverts, scapulars and the shape of the outermost rectrices (PRATER et al. 1977; CHYLARECKI 1985; KACZMAREK et al. 2007; WŁODARCZYK et al. 2008). 1198 of snipes were aged as first-year birds, 150 as adults and 35 individuals were not possible to be aged. 549 of first-year snipes were in an active moult. 
Moult data were recorded with usage of special moult cards. Tertials (TS) were numbered from distal (T1) to proximal (T5) side of the wing. Rectrices (RS) were divided into two symmetrical parts (L-left, R-right) and were numbered from outer (R1) to inner (R7) side of the tail. Each rectrix and tertial was denoted a moult score in the 5-point BTO scale (GINN, MELVILLE 1983). Lesser and median coverts were divided into three distinct groups of old (before shedding), growing and new feathers. Percentage of each category was recorded with a precision of $5 \%$. The fraction of growing body feathers (BF) was recorded within four different parts of body: head, back (including scapulars), belly feathers and tail coverts with the same precision. Moult indexes of tertials and rectrices were calculated as a sum of all moult scores of individual feathers (SNOw 1967; GINN, MELVILLE 1983). Moult index of wing coverts (WC) was expressed as a percentage of growing and new feathers altogether. Moult sequence within a given tract (RS, TS) was presented with the means of moult scores of particular feathers. Data from all individuals moulting the feather tract served for this purpose. Dependently on the advancement of moult following groups of first-year birds were distinguished: individuals before moult, individuals starting to moult (i.e. moulting only body feathers), and individuals in an intensive stage of moult (i.e. moulting lesser/median wing coverts, tertials or rectrices). In order to define a commencement of moult in different tracts of feathers following categories were assigned: rectrices - moult index $<4$, tertials - moult index $<2$, wing coverts - moult index $<20$.

Fractions of growing body feathers in different tracts were compared with usage of Friedman ANOVA. Kruskal-Wallis ANOVA was used in order to test the differences between moult scores of particular rectrices and tertials. Spearman correlations were used to check for the relationship between intensity/advancement of moult of different tracts of feathers. Interrelationship of moult progression of basic tracts of feathers (rectrices, tertials and wing coverts) was investigated with usage of homogeneity-of-slopes model. Statistical analyses followed ZAR (1996). 


\section{RESULTS}

\subsection{General moult scheme}

Moult was commenced in body feathers, during replacement of which birds started an intensive moult including lesser/median wing coverts, tertials and rectrices. Sequence of intensive post-juvenile moult showed high inter-individual variability. Data from 95 first-year Common Snipes caught just after commencement of moult showed that most frequently it was started in rectrices $(36.9 \%)$ or wing coverts $(25.3 \%)$, however there was also a small fraction of birds which started an intensive moult from tertials (8.4\%). $24.1 \%$ of birds commenced intensive moult simultaneously in two of these tracts of feathers (rectrices and tertials most frequently $-10.5 \%$ ). Moreover, $5.3 \%$ of birds started intensive moult in all three tracts of feathers at the same time. Moult indexes of wing coverts and of tertials correlated significantly with moult index of rectrices (wing coverts: $r=0.37$, $\mathrm{n}=152, \mathrm{P}<0.001$; tertials: $\mathrm{r}=0.45, \mathrm{n}=152, \mathrm{P}<0.001)$.

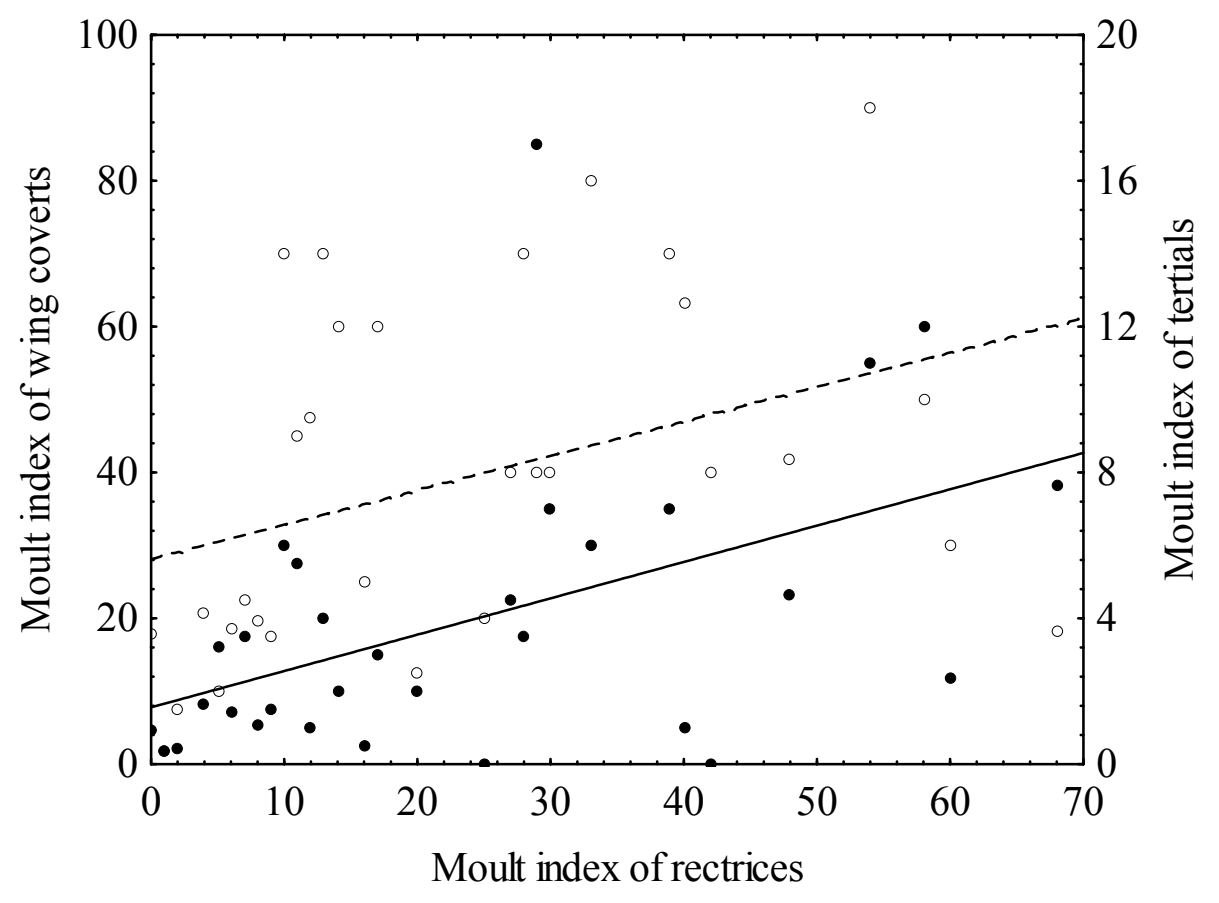

Fig. 1. Dependence of moult of lesser/medium wing coverts (white circles, dashed line) and tertials (black circles, solid line) on advancement of moult of rectrices in first-year snipes. 
In general, moult of rectrices was finished before completion of moult of wing coverts and tertials (Fig. 1). Moult of tertials was proceeding at the similar pace as moult of wing coverts (homogeneity-of-slopes model: $\mathrm{F}=0.69, \mathrm{df}=1, \mathrm{P}=0.42$ ), however, due to the late shedding of tertials this tract of feathers was the last to be completely moulted.

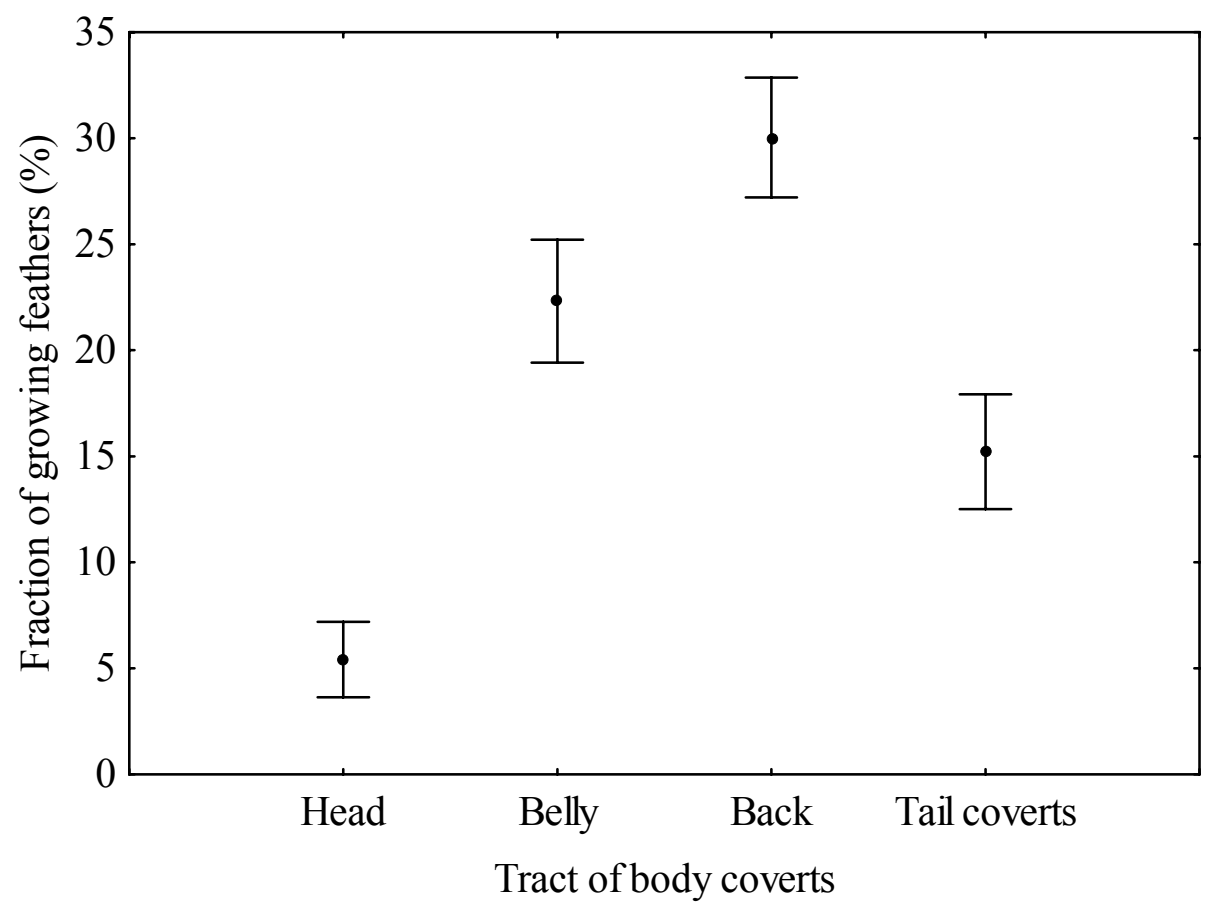

Fig. 2. Intensity of moult of different tracts of body feathers expressed by the fraction of feathers growing simultaneously. Central point - mean; whiskers $1.96 * \mathrm{SE}$.

\subsection{Body feathers}

Distinguished tracts of body feathers (i.e. head, back, belly feathers and tail coverts) were moulted with different intensity, as there were significant differences in the fraction of feathers growing simultaneously in each tract (Friedman ANOVA: $\chi^{2}=450.86, \mathrm{df}=3, \mathrm{P}<0.001$, Fig. 2). Head feathers were moulted with the lowest intensity (on average $5.4 \%$ of feathers growing simultaneously) in contrast to the back feathers, which were moulted in the most intensive way among distinguished 
tracts $(30.0 \%$ of feathers growing simultaneously). Moult of body feathers intensified when replacement of other tracts of feathers (i.e. tertials, rectrices or wing coverts) was commenced as significant increase in the fraction of growing body feathers was recorded at this point (Mann-Whitney U-test: $Z=7.05, \mathrm{n}_{1}=173$, $\left.\mathrm{n}_{2}=249, \mathrm{P}<0.001\right)$. Intensity of moult of tail coverts was associated with intensity of moult of rectrices, which was expressed as a number of simultaneously growing feathers $(\mathrm{r}=0.41, \mathrm{n}=149, \mathrm{P}<0.001)$.

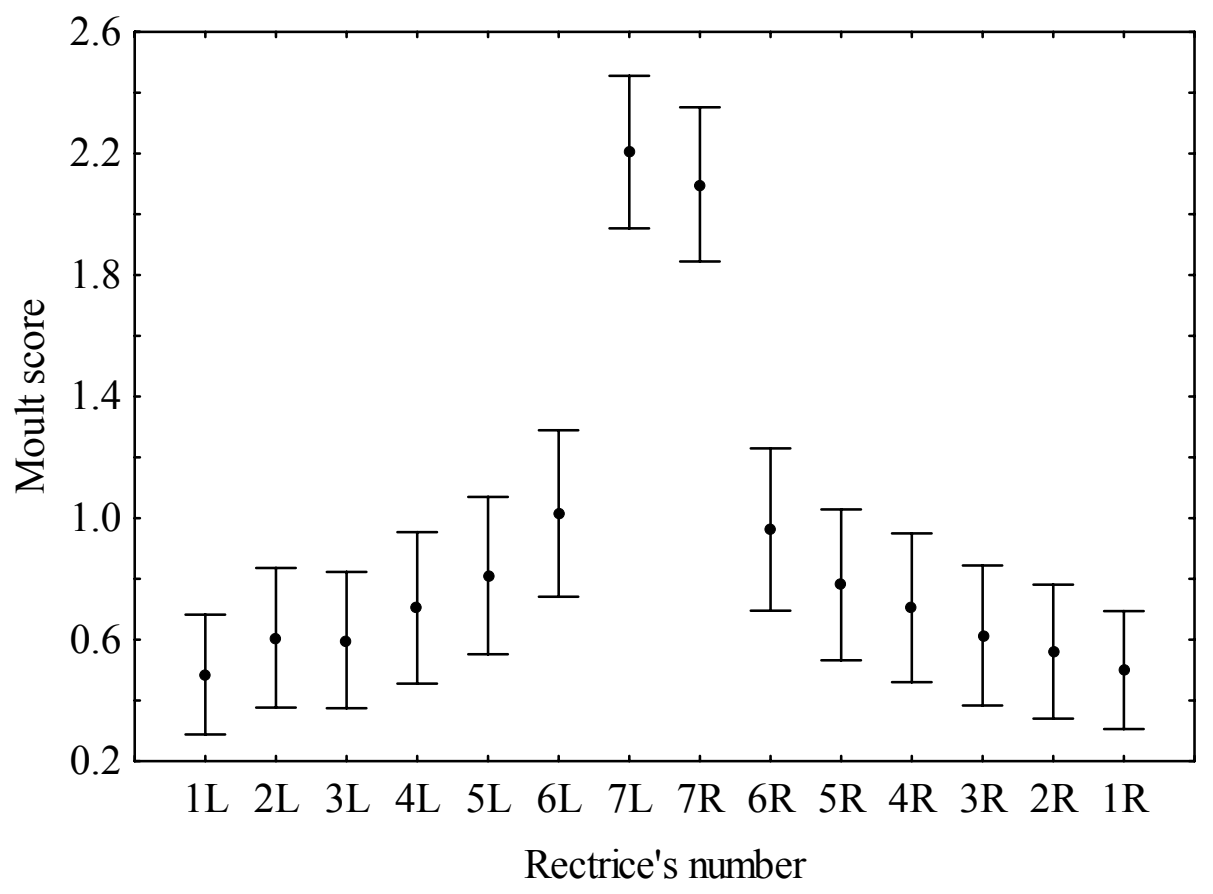

Fig. 3. Sequence of moult of rectrices in first-year snipes expressed by moult scores of particular feathers ( $\mathrm{L}$ - left side of the tail, $\mathrm{R}$ - right side of the tail). Central point - mean; whiskers $-1.96 * \mathrm{SE}$.

\subsection{Rectrices}

There were significant differences in the mean moult scores of particular rectrices (Kruskal-Wallis ANOVA: $\mathrm{H}_{13,1848}=401.57, \mathrm{P}<0.001$ ), which implied different times of their shedding. Moult of rectrices usually started from one (76\% of cases of centrifugal moult, $\mathrm{n}=110)$ or significantly less frequently from a few $(24 \%$, 
$\left.\chi^{2}=60.07, \mathrm{df}=1, \mathrm{P}<0.001\right)$ central pairs of feathers and was followed by centrifugal or irregular moult of the whole tail (Fig. 3). Differences in the moult scores were especially marked between central pair of rectrices and the rest of the feathers from this tract (Kruskal-Wallis multiple comparisons: all cases $\mathrm{P}<0.001$ ), since many birds finished growth of both central feathers before continuation of tail moult. Regular centrifugal moult was recorded in $87 \%$ of cases $(n=126)$ and was significantly more frequent than all other types of moult $\left(\chi^{2}=54.48, \mathrm{df}=1, \mathrm{P}<0.001\right)$. Simultaneous moult was recorded only in $2 \%$ of individuals and $11 \%$ of birds showed irregular moult.

\subsection{Tertials}

There was no case of moult of the outermost tertial (T1) in first-year birds, so it was excluded from further analyses. Mean moult scores of particular tertials differed significantly (Kruskal-Wallis ANOVA: $\mathrm{H}_{3,248}=53.28, \mathrm{P}<0.001$ ).

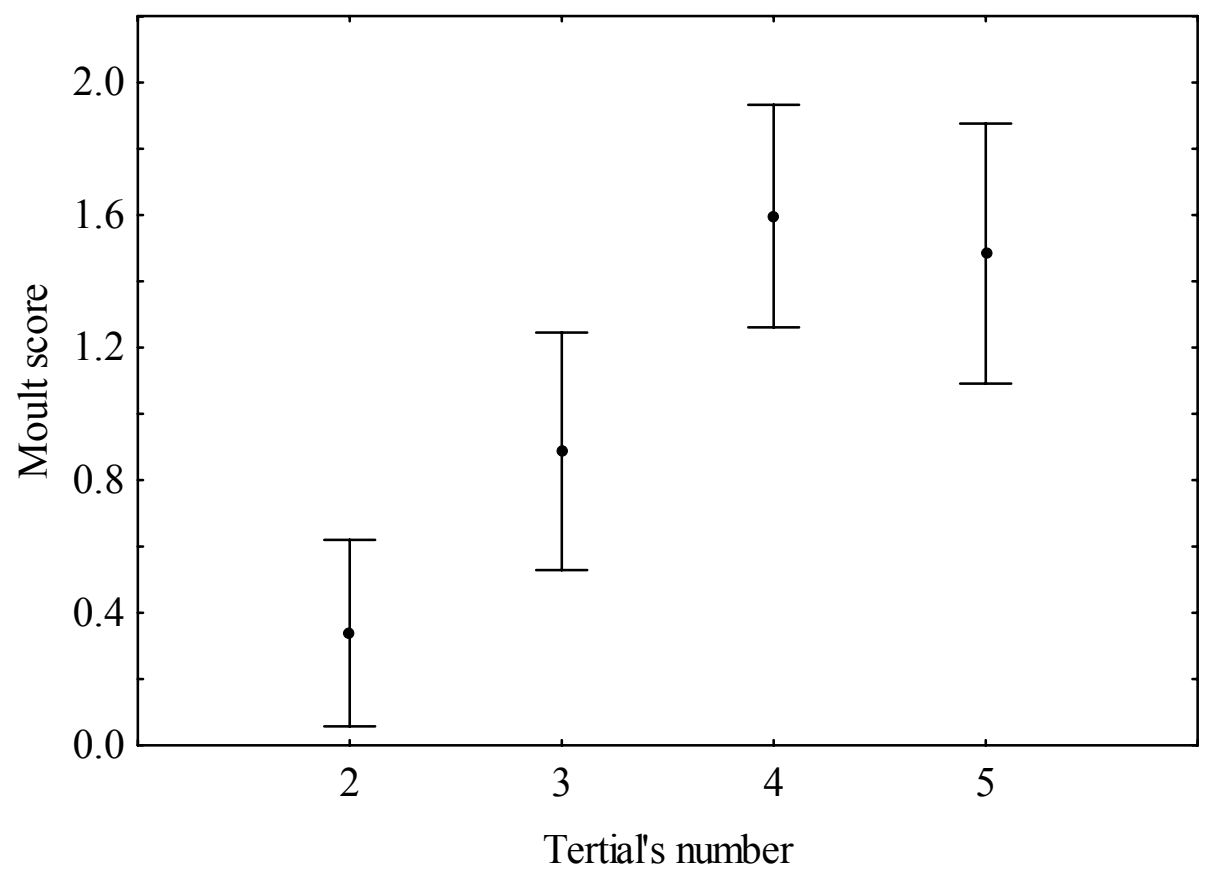

Fig. 4. Sequence of moult of tertials in first-year snipes expressed by moult scores of particular feathers. Central point - mean; whiskers $-1.96 * \mathrm{SE}$. 
Following schemes of moult of tertials were distinguished $(n=70)$ : moult starting from inner tertials and proceeding outwards (47\%), moult starting from outer tertials and proceeding inwards (9\%), centrifugal moult starting from middle tertials and proceeding in both directions (44\%). In general, two innermost tertials (T4-5) were moulted in the first place and T2 was moulted as the last feather from this tract (Fig. 4). Inter-wing asymmetry in moult of tertials was recorded in $15 \%$ of individuals.

\section{DISCUSSION}

Although sequence of post-juvenile moult of Common Snipe appeared to be individually variable, some general remarks upon the algorithm of ageing procedures of this species can be drawn from our results. Primarily, tertials turned out to be the most useful for ageing of first-year Common Snipes in an advanced stage of moult, as the juvenile feathers in this tract are usually retained longer than age-diagnostic feathers from other tracts. This is particularly valid in the late part of the autumn, when the number of individuals with few retained juvenile feathers is rapidly growing. Outer tertials should be of special interest during age identification procedures, as in most of the cases they are shed as the last ones from this feather tract. The difference between both generations of tertials concerns the shape of subterminal band which in juveniles is parallel to the edge of the feather, whereas in adult-type feathers appears to be rather irregular (WŁODARCZYK et al. 2008). Such age-specific patterning is lacking on the outermost tertial, so even though it is not changed during post-juvenile moult, attention should be focused on the second tertial from the distal side of wing. Both wings should be examined in case of any uncertainties, since first-year snipes appeared to show relatively high inter-wing asymmetry of the moult of tertials. Lesser and median wing coverts might be also useful in age determination of birds in advanced moult stage. Contrastingly, rectrices occurred to be of limited usefulness for ageing purposes. Their moulting in first-year birds is usually finished well before all wing coverts and tertials are changed. Nevertheless, due to high frequency of regular centrifugal moult of tail, the outermost rectrices should be primarily examined. This is particularly advisable, as the age-specific differences are most strongly pronounced in this pair of rectrices. 
This is manifested by much shorter length and lack of characteristic incision in the inner web of juvenile feathers (PRATER et al. 1977). As snipes start post-juvenile moult from body feathers, scapulars are likely to be shed fairly quickly and soon replaced with adult-type fathers, which makes them useless in age identification of birds during later parts of autumn.

Since moult progression of any individual may be considered only in relation to the stage of migration and the time of the season, phenological studies on the moult stage at different stopover sites are desirable. In waders, length of migration is known to be one of the main determinants of moult onset (HoLMES 1971). Longdistance migrants, like Little Stint (Calidris minuta), Curlew Sandpiper (Calidris ferruginea) or Wood Sandpiper (Tringa glareola), usually do not start moulting before they reach wintering grounds in the temperate climatic zones of the southern hemisphere (MidDLEMISS 1961; ELLIOTT et al. 1976). By contrast, waders which cover relatively short distances during the autumn migration start and in many cases may finish moult still being en route. Such situation is typical for Common Snipe and many other species with short migration distance, including, for instance, some populations of Dunlin (Calidris alpina), Purple Sandpiper (Calidris maritima) or Grey Plover (Pluvialis squatarola) (Holmes 1966; BengTson 1970; SuMMERS et al. 2004; SERRA et al. 2006). At Jeziorsko reservoir first-year snipes which started moult in body feathers were recorded since the middle of July, whereas intensively moulting birds appeared at the beginning of August (MinIAS et al. 2010). A fraction of completely moulted first-year snipes did not exceed $10 \%$ of all caught birds at the end of September (unpublished data). Contrastingly, as much as 52\% of first-year birds did not yet begin post-juvenile moult at this time of year (MINIAS et al. 2010). This implicates that the majority of first-year birds finish post-juvenile moult on the further stages of migration or at wintering grounds. Similar situation was found during the studies in western Germany (OAG MÜNSTER 1975), where approximately half of first-year snipes caught in the middle of September did not start moulting. The fraction was, however, rapidly falling to $10 \%$ at the beginning of October. In Denmark individuals with juvenile feathers were still recorded in November (GLUTZ VON BLOTZHEIM et al. 1977). In conclusion, our results suggest that at least until the 
end of September only minor fraction of first-year snipes is not possible to be aged on the basis of plumage characteristics during autumn passage through Central Europe. Majority of first-year birds migrating through this part of continent finish post-juvenile moult at the beginning of October occasionally retaining some juvenile feathers until November (GLUTZ VON BlotzheIM et al. 1977). At this time of autumn migratory period existing ageing techniques start to be inapplicable in Common Snipe, what creates an urgent need for their further improvement.

\section{Acknowledgements}

We thank all participants of the fieldworks at the Jeziorsko reservoir, especially Rafał Bargiel, Anna Kleszcz and Łukasz Krajewski.

\section{REFERENCES}

BARgiel, R., WŁodArczYK, R., KAliŃSKI, A. 1998. Catching waders at the Jeziorsko reservoir (western Poland). Ring 20: 77-82.

Bengtson, S.A. 1975. Timing of the moult of the Purple Sandpiper Calidris maritima in Spitsbergen. Ibis 117: 100-102.

BUSSE, P. 2000. Bird station manual. Gdańsk.

ChYlarecki, P. 1985. Oznaczanie wieku u bekasa Gallinago gallinago. Biuletyn Polskiej Stacji Ornitologicznej 9: 30-36.

Devort, M. 1997. The Common Snipe. Elements for an action plan. OMPO. Paris.

GinN, H.B., Melville, D.S. 1983. Moult in Birds. BTO Guide number 19. Tring: British Trust for Ornithology.

Glutz von Blotzheim, U.N., BAuer, K.M., Bezzel, E. 1977. Handbuch der Vögel Mitteleuropas. Bd. 7 Akad. Verlagsges. Wiesbaden.

GREEN, R.E. 1991. Sex differences in the behavior and measurements of common snipes (Gallinago gallinago) in Cambridgeshire, England. Ringing and Migration 12: $57-60$.

Elliott, C.C.H., Waltner, M., Underhill, L.G., Pringle J.S., Dick, W.J.A. 1976. The migration system of the Curlew Sandpiper Calidris ferruginea in Africa. Ostrich 47: 191-213. 
Fogarty, M.J., Arnold, K.A., McKibben, L., Pospichal, L.B., Tully, J. 1977. Common Snipe. In: G.C. SANDERSON (ed.), Management of migratory shore and upland game birds. International Association of Fish and Wildlife Agencies. Washington, D.C., USA, pp. 189-209.

HoffPAuiR, J.W. 1969. The development of external aging and sexing techniques and trapping methods for common snipe (Gallinago gallinago delicata) in Louisiana. Thesis, Louisiana State University, Baton Rouge, Louisiana, USA.

HoLmes, R.T. 1966. Breeding ecology and annual cycle adaptations of the Redbacked Sandpipers (Calidris alpina). Condor 68: 3-46.

HoLmES, R.T. 1971. Latitudinal differences in the breeding and and schedules of Alaskan Red-backed Sandpipers (Calidris alpina). Condor 73: 93-99.

Janiszewski, T., WŁodarczyK, R., Bargiel, R., Grzybek, J., Kaliński, A., Lesner, B., MielczareK, S. 1998. Avifauna of Jeziorsko reservoir in the years 1989-1996. Not. Ornit. 39: 121-150. [In Polish with English summary].

Kaczmarek, K., Minias, P., WŁodarczyk, R., Janiszewski, T., Kleszcz, A. 2007. A new insight into the ageing of Common Snipe Gallinago gallinago - the value of contrast within the wing-coverts of adults. Ringing and Migration 23: 223-227.

McCloskey, J.T., Thompson, J.E. 2000. Ageing and sexing Common Snipe using discriminant analysis. J. Wildl. Mgmt. 64: 960-969.

MidDLEMISS, E. 1961. Biological aspects of Calidris minuta while wintering in South-West Cape. Ostrich 32: 107-121.

Minias, P., Kaczmarek, K., WŁodarczyK, R., JANisZewski, T. 2010. Adjustments and exploitation of body stores during post-juvenile moult in Common Snipe Gallinago gallinago. Waterbirds 33: 116-120.

OAG MÜNSTER. 1975. Migration, moult and biometry of the Snipe (Gallinago gallinago) in the sewage farms Münster. J.Orn. 116: 455-487. [In German with English summary].

Prater, A.J., Marchant J.H., VuOrinen, J. 1977. Guide to the identification and ageing of Holarctic waders. BTO Guide number 17. Tring: British Trust for Ornithology. 
RouXEL, R. 2000. Snipes of the Western Palearctic. Ed. OMPO. Eveil Nature, Saint Yrieix sur Charente, France.

SÆTHER, S.A., KÅLÅS, J.A., FiSKE, P. 1994. Age determination of breeding shorebirds: quantification of feathers wear in the Lekking Great Snipe. Condor 96: 959-972.

Serra, L., Clark, N.A., Clark, J.A. 2006. Primary moult, body mass and migration of Grey Plovers Pluvialis squatarola in Britain. Ibis 148: 292-301.

SNOW, D.W. 1967. A Guide to Moult in British Birds. BTO Guide noumber 11. Tring: British Trust for Ornithology.

StRANDGAARD, K. 1986. Ageing and sexing of the Common Snipe (Gallinago gallinago). Proc. Third European Woodcock and Snipe Workshop. Paris, France, pp. 24-36.

Summers, R.W., Underhill, L.G., Nicoll, M., StranN, K-B., Nilsen, S.Ø. 2004. Timing and duration of moult in three populations of Purple Sandpipers Calidris maritima with different moult/migration patterns. Ibis 146: 394-403.

TomiałojĆ, L., Stawarczyk, T. 2003. Avifauna of Poland. Distribution, numbers and changes. PTPP "pro Natura” Wrocław. [In Polish with English summaries]

TUCK, L.M. 1972. The snipes: a study of a genus Capella. Canadian Wildlife Service Monograph Series 5.

WhITEHEAD, C.J. 1965. Foods and feeding habitats of the common snipe (Capella gallinago delicata) in Cameron Parish, Louisiana, with ecological notes and a discussion of methods of sexing and aging. Thesis, Louisiana State University, Baton Rouge, Louisiana, USA.

WŁodarczyK, R., KaczmareK, K., Minias, P., Janiszewski, T. 2008. Ageing and sexing of the Common Snipe Gallinago gallinago gallinago. Wader Study Group Bull. 115: 45-49.

ZAR, J.H. 1996. Biostatistical Analysis, 3rd ed. Prentice-Hall, London. 